\title{
A Blockchain Technology for University Thesis Grading
}

\author{
Bagus Afan Herlambang ${ }^{1}$, Renny Triana ${ }^{2}$, Yonathan Gunawan $^{3}$, Sfenrianto $^{4}$ \\ ${ }^{1234}$ Information Systems Management Department, BINUS Graduate Program - Master of Information Systems \\ Management, Bina Nusantara University, Jakarta 11480 \\ ${ }^{1}$ bagus.herlambang@binus.ac.id; ${ }^{2}$ renny.triana@binus.ac.id; ${ }^{3}$ yonathan.gunawan001@binus.ac.id; \\ ${ }^{4}$ sfenrianto@binus.edu
}

\begin{abstract}
Technological development increases rapid growth, including in the world of education. Education is important in creating superior national seeds. An important component in education problems that are often found in the evaluation system in the thesis process at the university often occurs data manipulation. The research aims to design the idea of applying Blockchain-Based Technology to the thesis discussion system at universities. Forum Group Discussion (FGD) is used to collect data related to business processes in the thesis assessment from beginning to end. The literature review is used as a means to support the theories or hypotheses proposed in this study. Therefore, this research proposes to give the idea of designing a system. Assessing the thesis uses Blockchain-Based Technology to eliminate cheating in practice and can also increase the potential in the world of education so that it can move forward in this era.
\end{abstract}

Key words : Blockchain Technology, Thesis, Grading, Forum Group Discussion (FGD)

\section{INTRODUCTION}

The thesis is the end of the process of lecturing a student at the university. After the thesis writing process has been completed, the supervisor will provide the guidance value, after that the student follows the thesis session and gets the grade from the examiner. The value component of the supervisor and thesis examiner determines the final grading of the thesis graduation. Changes in the value of vulnerability occur from what has been said by the Supervisor or Examiner or supporting unit.

On the other hand Blokchain Technology has been widely used in various fields, including education. There is technology that can help with thesis value process problems, namely the Blockchain Technology which was established by Satoshi Nakamoto [1] in 2008 is believed to facilitate the problem, and some characteristics of Blockchain Technology changed, can reliable, valid and distributed. This is because documents only produce once and can never be reproduced or changed forever [2]-[5].

At present, grades from supervisors and thesis examiners have been recorded in the application, and the application also helps to combine the two values into the final grade of the thesis subject. After that, the value section also helps validate the hard copy of value files from the supervisor and examiner with the results of data collection conducted by the unit responsible for the thesis session implementation. But the vulnerability of cheating to manipulate thesis value data remains unavoidable, because there are still gaps in the data center where data can still be updated so that it affects the student cumulative achievement index, and it can be concluded that the current application is not optimal in terms of data security. So we need Blockchain-Based Technology that can solve this problem. This research was created to maintain data security, ensure data validity so that data is not manipulated. Blockchain technology provides a reliable and secure way of carrying out the transactions by different applications in a distributed environment. The transactions carried out cannot modified by any participating entity in the blockchain [6].

This research will try to describe the thesis process based on the thesis business process value chain. This research was conducted using qualitative methods, focus group discussions with related units within the university and Blockchain Technology experts, to validate the process. The purpose of this study is to create a Blockchain-Based Technology model for the thesis process. By using Blockchain-Based Technology, manipulation of information or data on student thesis scores can be avoided. In the end, the thesis value can be more reliable, unchanged, can be distributed, and safe. Blockchain Technology helps to provide the security to the data by using the previous key to the server and the data is confidentiality protected [7]. 


\section{LITERATURE REVIEW}

Several studies report Blockchain Technology can be applied to solve the problem of data being misused so as to harm customers [8]. However, previous research has shown that taking data on smart grid networks and making block chain is simple, but this research will focus on the detailed process or business operation process within the university where Blockchain Technology is useful to facilitate problems. Then there is also research that says that Blockchain Technology can be used to verify student learning achievement [9]. However, in this research there are challenges related to security, privacy, cost, scalability, and availability before adopting Blockchain Technology.

Blockchain Technology was founded by a person or group named Satoshi Nakamoto [1] as an exhibition in Figure 1. The first time, this blockchain was used by Bitcoin or virtual currencies and the recent development of Blockchain Technology can be used for enterprise systems.

There are several mechanisms that exist in the blockchain so that security can be maintained [10]:

\section{A. Hash Mechanism}

The hash technique is a cryptographic technique which is a mathematical algorithm that maps random data in a fixed-size string and is designed to be a one-way function that allows the function cannot be returned to its previous state. So that it can be said that if an information, after the hash has been made using cryptographic hashes, the digital sign is unique and cannot be reversed to its origin.

\section{B. Proof of Work Mechanism}

This mechanism is to slow down new blocks with the aim that the process of calculating proof of work blocks can be maintained.

\section{Peer to Peer Mechanism}

This mechanism serves to distribute user transactions that are incorporated in peer to peer blockchain networks. In essence, this mechanism will work as follows: when someone has just joined a peer to peer network will get a complete copy of the transactions that occur in that network. If at any time a new transaction occurs, the new information will be thrown to all users for verification. After the validation process is complete, the block will be recorded in each user's blockchain.

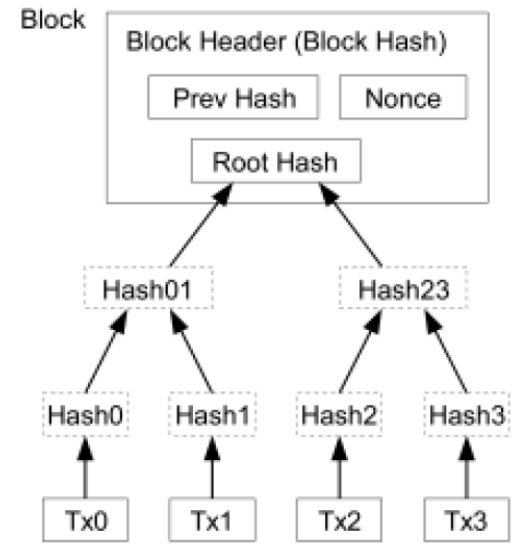

Figure 1: Blockchain Technology

\section{METHODOLOGY}

This section will explain the methodology used in research. This research will focus on the current thesis process which is obtained based on the FGD (Forum Group Discussion) method, then after consulting with related units within the university and also Blockchain Technology experts, it is proposed to design a thesis process with Blockchain-Based Technology, this can be seen in Figure 2.

FGD is one of the qualitative methods used in this study. FGD's have been conducted to discuss business processes or educational value chains and also validate the proposed model.

The thesis process is one of the important processes in a series of operational processes in a university where students become an undergraduate must go through this process. This activity plays an important role in ensuring students are enrolled in the system as participants of the thesis and will finally be tried and processed for graduation graduation to get the status of their study graduation. However, the system or database is easily manipulated as the value of the supervisor or examiner. Therefore, based on Blockchain-Based Technology will be adopted in the thesis process, especially the value of data collection.

There are parties who will be involved in this process, which are as follows:

\section{A. Student Registration}

In this section, student registration will ensure that a student meets the requirements for thesis subject registration.

\section{B. Finance}

In this finance section, will ensure the payment process is carried out by students. 


\section{Study Program}

In this section, the Study Program will ensure students get supervisors to provide thesis guidance and get examiner lecturers in accordance with the student's thesis topic.

\section{Student}

As people who will undergo thesis courses in the semester.

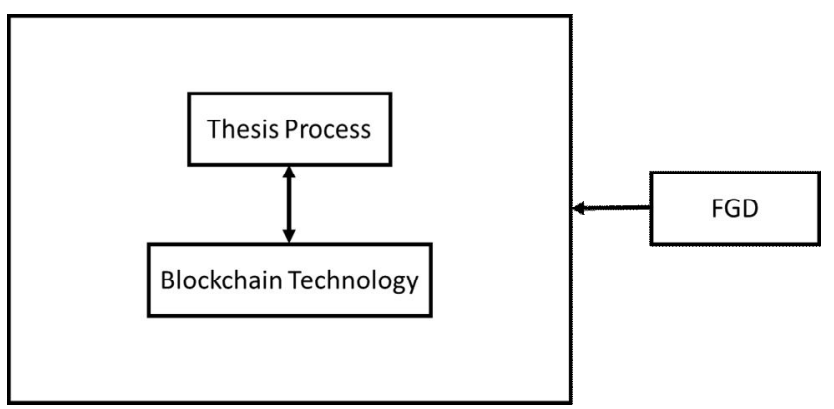

Figure 2: Research Design Stages

\section{RESULT AND DISCUSSION}

\subsection{Thesis Business Process}

The thesis business process at this time is in the process of making proposals and the appointment of a Supervisor. Students make a proposal and are reviewed by the Study Program. This section is the beginning of the thesis process. Then proceed with the thesis guidance process and giving grades from the Supervisor. This process is very important and vulnerable to be modified by people who are not authorized by the current system.

For the thesis trial process and the grading of examiners, students who have done the guidance will undergo a thesis trial. Then the examiner will give a value of the results of the trial.

And the last is the thesis grade validation process, where the unit value section will validate the value of the Supervisor and Examiner inputted by the support unit, and ensure that the grade resulting from the merging of the two component values is correct.

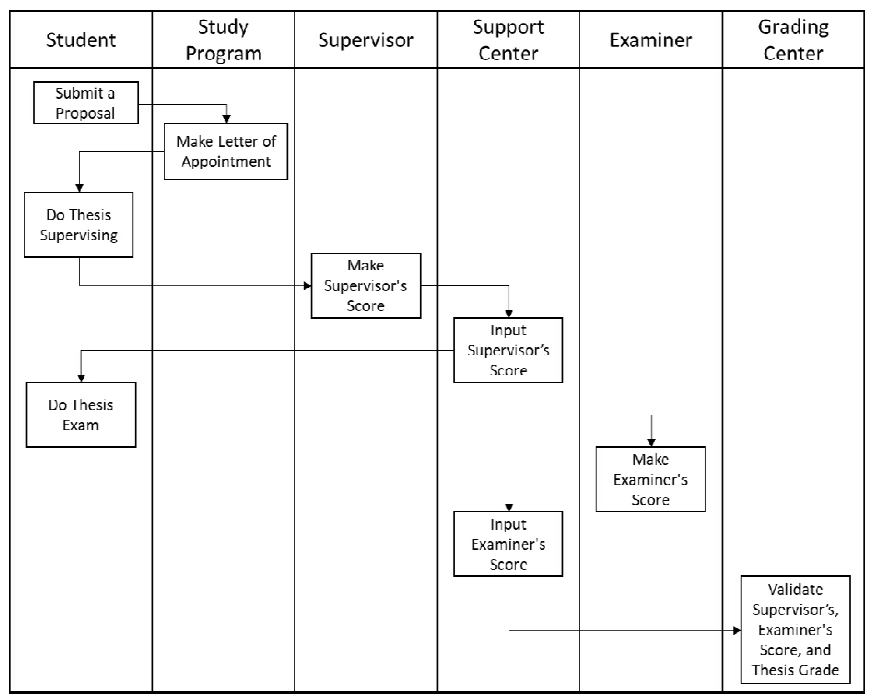

Figure 3: Current Thesis Process

\subsection{Thesis Business Process based on Blockchain Technology}

The proposed Blockchain-Based Technology design can be seen in Figure 4. Blockchain-Based Technology in the thesis process will be integrated between students, Supervisor, Examiner, value units, and supporting units, compared to the current system version, later on the process manipulation and also data manipulation cannot occur.

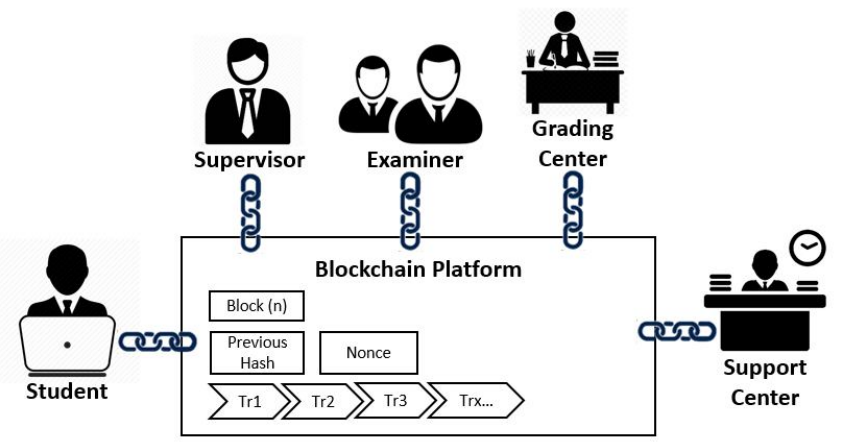

Figure 4: Blockchain-Based Technology Design

Details of the thesis process can be seen in Figure 5, were in the process of making a proposal and the appointment of a Supervisor up to the thesis guidance process there is still no change to the previous process.

There is a change in the grading process of the Supervisor who will implement Blockchain-Based Technology. This process is very important and vulnerable to be modified by people who are not authorized by the current system. Therefore, this process will be added to the Blockchain-Based Technology by recording grades given by the Supervisor. By using Blockchain Technology, Supervisor and support units can monitor changes or transactions that occur.

Then changes also occur in the process of grading the examiner for students who undergo a thesis trial. This process will be added to Blockchain-Based Technology. This value can be monitored by examiners and support units. And the last change is the thesis grade validation process when the unit value section will validate the value of the Supervisor and Examiner. This section will be recorded in Blockchain-Based Technology to ensure thesis grade obtained by students. Blockchain-Based Technology in the thesis process will improve the supervision of the thesis activity to ensure the value of the Supervisor, the value of the Examiner, and the grade of the thesis is correct and valid, this change is seen in Figure 5. 


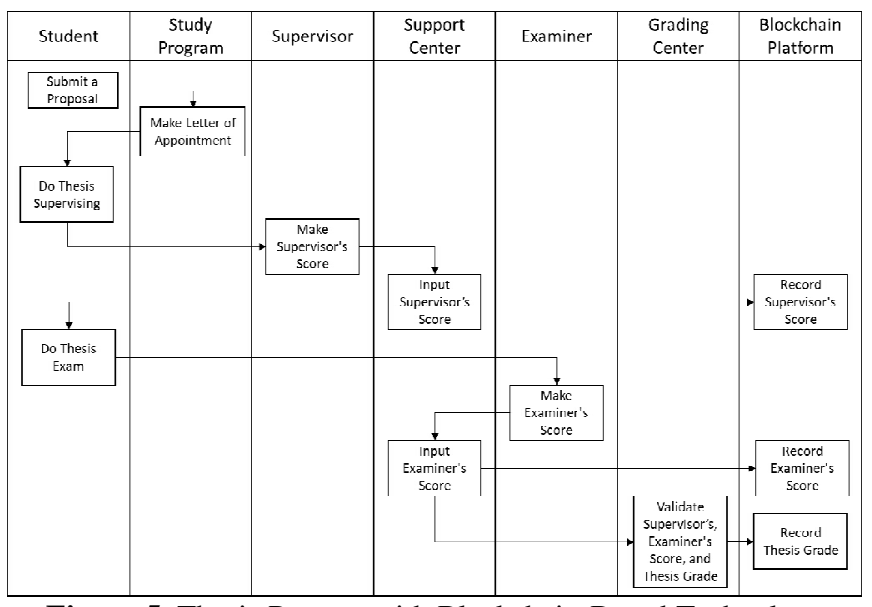

Figure 5: Thesis Process with Blockchain-Based Technology

\section{CONCLUSION}

The thesis process without Blockchain-Based Technology is indicated to have a vulnerability to cheating to manipulate thesis value data that remain unavoidable, because there are still gaps in the data centre where the data can still be updated so that it affects the student cumulative achievement index, and it can be concluded that the current application is not optimal in terms of data security.

Blockchain-Based Technology has many benefits for the University's operational processes such as Supervisor scores record, Examiner score records, and student thesis final note records, in this case the validity of the value data obtained by students, therefore using Blockchain-Based Technology can minimize errors and manipulation of Supervisor scores, Examiner scores, and final thesis grades. Blockchain-based technology opens the possibility for universities maintain the validity of thesis grades that are safe for students and can also be used by other universities.

\section{REFERENCES}

1. S. Nakamoto, Bitcoin: A Peer-to-Peer Electronic Cash System, 2008.

2. A. Alammary, S. Alhazmi, M. Almasri, and S. Gillani, Blockchain-Based Applications in Education: A Systematic Literature Review, Appl. Sci., vol. 9, 2019. https://doi.org/10.3390/app9122400

3. D. J. Skiba, The Potential of Blockchain in Education and Health Care, Nurs. Educ. Perspect., vol. 38, no. 4, pp. 220-221, 2017.

4. $\mathrm{K}$. Al Harthy, The upcoming Blockchain adoption in Higher-education: requirements and process, 2019 4th MEC Int. Conf. Big Data Smart City, pp. 1-5, 2019. https://doi.org/10.1109/ICBDSC.2019.8645599

5. M. Turkanovic, M. Holbl, K. Kosic, M. Hericko, A. Kamisalic, and M. Turkanovi, EduCTX: A blockchain-based higher education credit platform, IEEE Access, vol. X, no. January, pp. 1-15, 2018. https://doi.org/10.1109/ACCESS.2018.2789929
6. Vijaya Murari T1, Dr. Ravishankar K.C., Blockchain Technology, Use cases and Content Delivery Network, International Journal of Advanced Trends in Computer Science and Engineering, Vol 9 No.2, March April 2020, https://doi.org/10.30534/ijatcse/2020/109922020.

7. Ch. Himaja, Y. Sriram Chowdary, Dr Amarendra K, Dr S Ananthakumaran, An Effective Method to Secure Electronic Health Record Based on Block Chain Technology, International Journal of Advanced Trends in Computer Science and Engineering, Vol. 9 No.2, March - April 2020, https://doi.org/10.30534/ijatcse/2020/110922020

8. Hafizh Fianto Putra, Wirawan, Ontoseno Penangsang, Penerapan Blockchain dan Kriptografi untuk Keamanan Data pada Jaringan Smart Grid, Jurnal Teknik ITS Vol. 8, No. 1, 2019. https://doi.org/10.12962/j23373539.v8i1.38525

9. Ali Alammary, Samah Alhazmi, Marwah Almasri, dan Saira Gillani, Blockchain-Based Applications in Education: A Systematic Review, 2019. https://doi.org/10.3390/app9122400

10. Pearce, Blockchain in Academia: A Literature Review, 2019 